\title{
59 THE ROLE OF OESOPHAGEAL STENTS IN THE MANAGEMENT OF OESOPHAGEAL ANASTOMOTIC LEAKS AND BENIGN OESOPHAGEAL PERFORATIONS
}

B Dasari, D Neely, A Kennedy, G Spence, P Rice, E Mackle, E Epanomeritakis Belfast Health and Social Care Trust, Ulster Hospital, Craigavon Area Hospital, Northern Ireland

\subsection{6/gutjnl-2013-305143.59}

Introduction Endoscopic placement of oesophageal stent across the benign oesophageal perforation and postoperative oesophageal anastomotic leak might help to control the sepsis and reduce the associated mortality and morbidity.

Aims/Background The aim of this review is to assess the safety and effectiveness of oesophageal stents in the management of benign oesophageal perforation and oesophageal anastomotic leaks.

Method All the published case series reporting the use of metallic and plastic stents in the management of postoperative anastomotic leaks, spontaneous oesophageal perforations, iatrogenic oesophageal perforations were identified from MEDLINE, EMBASE and PUBMED (1990-2012). Primary outcomes assessed were technical success rates and complete healing rates. Secondary outcomes assessed were stent migration rates, stent perforation rates, duration of hospital stay, time to stent removal and mortality rates. A pooled analysis was performed and subgroup analysis was performed for plastic vs metallic stents and anastomotic leaks vs perforations separately.

Results 27 case series with 340 patients were included. Technical and clinical success rates of stenting were $91 \%$ and $81 \%$ respectively. Stent migration rates were significantly higher with plastic stents compared to metallic stents (40/148 vs $13 / 117$ patients respectively; $p=0.001)$. Patients with metallic stents had significantly higher incidence of post procedure strictures $(p=0.006)$. There was no significant difference in the primary or secondary outcomes when stenting was performed for anastomotic leaks or perforations.

Conclusion Endoscopic management of oesophageal anastomotic leaks and perforations with the use of oesophageal stents is technically feasible. It appears to be safe and effective when performed along with mediastinal or pleural drainage. 